\title{
LA UTOPÍA MULTICULTURAL
}

Daniel Loewe

De acuerdo al artículo una utopía multicultural, entendida como una estructura social y jurídica que garantiza a todos los grupos culturales y religiosos suficiente espacio para poder desarrollar todas sus prácticas tradicionales, es una anti-utopía en la cual los derechos de muchos pueden ser violados en nombre de la cultura. Una política multicultural que no viole los derechos de los individuos debe reconocer y respetar su libertad para definir y redefinir constantemente su identidad del modo que consideren apropiado.

Palabras claves: Multiculturalismo; Utopía; Relativismo; Identidad; Derechos Culturales.

Imagine una sociedad que ofrece suficiente espacio jurídico y social para que todos los grupos culturales y sus miembros puedan desarrollar cada una de sus prácticas culturales tradicionales. Esta idea sería la expresión máxima del concepto de "ciudadanía diferenciada"1 o "ciudadanía multicultural"2. Lo que caracterizaría a la esta sociedad sería la diferencia en derechos y obligaciones de los ciudadanos en razón de su cultura y, por extensión, religión. ${ }^{3}$

\footnotetext{
* Daniel Loewe es Doctor en Filosofía de la Universidad Eberhard-Karls de Tübingen. Es profesor titular de filosofía política de la Escuela de Gobierno de la Universidad Adolfo Ibáñez en Santiago de Chile. También es miembro del Research Centre for Political Philosophy y del International Centre for Ethics in the Sciences and Humanities (IZEW) de la universidad de Tübingen. E-mail: daniel.loewe@uai.cl. Santiago/Chile.

${ }^{1}$ YOUNG, Iris Marion. Justice and the Politics of Difference.

${ }^{2}$ KYMLICKA, Will. Multicultural Citizenship.

${ }^{3}$ Esto no quiere decir que el único modo de garantizar suficiente espacio para que los grupos culturales puedan desarrollar sus prácticas tradicionales sea mediante un sistema de derechos culturales. Otra posibilidad es un sistema libertario en el cual el Estado no se inmiscuye de ningún modo, tampoco garantizando derechos culturales, en las actividades de los grupos, en tanto éstos respeten el derecho de salida de sus miembros. Esta es la propuesta de Kukathas ("Are there any cultural rights?"; IDEM. "Cultural Toleration"; IDEM. The liberal archipelago), a la que no me referiré en este texto.
} 
En esta sociedad los Sikh podrían conducir motocicleta sin casco en tanto vistan un turbante. Musulmanes practicantes podrían ser maestros de tiempo completo aunque no puedan cumplir con el horario establecido, si éste colide con la obligación religiosa de asistir a la mezquita los viernes en la tarde. Amish, así como otros grupos de cristianos fundamentalistas, podrían retirar a sus hijos de la escuela antes de lo que la ley establece, o incluso, no enviarlos. Grupos religiosos podrían exigir que se retiren ciertas materias del plan de estudio escolar (por ejemplo, la teoría de la evolución de Darwin) y se agreguen otros (por ejemplo, el creacionismo). Grupos étnico-culturales y religiosos recibirían financiamiento público para fundar y administrar sus propias escuelas. Regiones con concentraciones lingüísticas podrían hacer vinculante el idioma de enseñanza en todos los niños que habitan en ella. Se podría sacrificar animales con fines culinarios o ceremoniales de acuerdo a los ritos propios de ciertas religiones (Sechita en el caso de los judíos; Halah en el de los musulmanes; Evö en el del Candomblé), aunque esto colida con la legislación acerca del trato de los animales. Se asignarían fondos públicos destinados a fortalecer las identidades, por ejemplo mediante el financiamiento del arte étnico, programas de radio y televisión, etc. Se restringiría la libertad de expresión y artística para evitar violar la sensibilidad de grupos culturales y religiosos. El derecho de familia de cada grupo, cultural o religioso, se organizaría de acuerdo a las tradiciones que reglan esas relaciones. Así serían posibles los matrimonios forzados, de niños, o la desigualdad de derechos con respecto al divorcio. Grupos indígenas podrían hacer completamente vinculantes sus concepciones acerca de las condiciones de membrecía en sus grupos aunque al hacerlo violen otros derechos, incluso cuando son reconocidos constitucionalmente. Asociaciones educativas, comerciales, o con cualquier otro fin, podrían establecer sus criterios de inclusión y exclusión de acuerdo a la doctrina cultural y religiosa que los convoque. Se podrían desarrollar todas las prácticas en sintonía cultural o religiosa que marcan (por cierto, no sólo simbólicamente) etapas importantes en el ciclo de la vida, como el nacimiento, el paso a la adultez y la muerte. Aquí se inscriben prácticas como, por ejemplo, la mutilación genital femenina o la circuncisión masculina, la realización de cortes en la cara o el cuerpo, la deformación de miembros, la quema de viudas, y los entierros fluviales. El derecho penal estaría en sintonía con los aspectos propios de cada cultura, aceptando la defensa cultural y rebajando el grado de la pena, o anulando el delito, si los hechos imputados no son 
punibles dentro de la cultura. Por ejemplo, en el caso del linchamiento de presuntos delincuentes, o el asesinato de honor.

Podríamos seguir agregando casos a esta lista de un modo casi interminable. Todos los casos mencionados refieren a demandas que se han presentado y defendido, ya sea en la academia o en las cortes, en nombre del multiculturalismo. Algunas han sido reconocidas en algunas jurisdicciones y otras no. Otras existen con independencia de la política multicultural. Algunas parecen no ser problemáticas. Otras inaceptables. Un significado usualmente atribuido al término utopía es el de un plan ideal irrealizable al momento de concebirse, pero un plan inspirador que nos debiese guiar. ¿Corresponde la sociedad descrita a una utopía multicultural - es decir, un plan ideal acerca del modo de reglar las relaciones entre las culturas o religiones, el Estado y los individuos?

En este artículo pretendo investigar críticamente la idea de la ciudadanía multicultural. Muchas de las motivaciones que están a la base de diversas demandas que se han realizado en nombre del multiculturalismo son loables. Sin embargo, en muchos casos sus consecuencias sociales han sido objeto de fuertes críticas. Para esto procedo en cinco pasos. En primer lugar me refiero, muy someramente, al concepto de multiculturalismo. Luego indago algunos problemas relacionados con el convencionalismo y el relativismo cultural. En tercer me refiero a políticas multiculturales que en su justificación recurren al valor de la igualdad. En cuarto lugar indago críticamente la concepción de identidad a la base de muchas demandas multiculturales. Finalmente realizo algunas consideraciones.

\section{Las demandas multiculturales}

El tema del multiculturalismo no es nuevo. En la antropología social y en la sociología se recurría al término de sociedades plurales, para caracterizar sociedades con grupos (étnicos, religiosos) distintos y relativamente separados que confluyen en el mercado. ${ }^{4}$ En la literatura multicultural actual se recurre frecuentemente a la diversidad cultural que se relaciona con los grupos indígenas, las naciones minoritarias, los grupos religiosos y los inmigrantes. En buena medida, con los procesos migratorios se sitúa la diferencia cultural del inmigrante en el centro de lo que se suponía, usualmente de un modo incorrecto, como un contexto social relativamente homogéneo. Irónicamente, lo que en la

\footnotetext{
${ }^{4}$ SMITH, M.G. The plural society in British West Indies; FURNIVALL, John S. Colonial Policy and Practice.
} 
actualidad otorga al tema multicultural una cierta urgencia, es, entre otras cosas, el éxito logrado con el reconocimiento de los derechos humanos y fundamentales entendidos como universales, individuales e inviolables. Este entendimiento afina la sensibilidad hacia las situaciones de opresión, dominación e injusticia de las que son víctimas muchos miembros de grupos culturales que usualmente constituyen minorías. La solución parece ser, entonces, ampliar la gama de bienes jurídicos protegidos, e incluir elementos como la integridad cultural. Los derechos liberales clásicos, que junto a los derechos políticos y a los derechos sociales, por ejemplo Marshall ${ }^{5}$ caracteriza como un proceso de inclusión social continuada, y que a un nivel filosófico alcanzan un alto grado de aceptación con la teoría de la justicia articulada por John Rawls ${ }^{6}$, tendrían que ser complementados con derechos culturales.

A grandes rasgos, el multiculturalismo es un programa normativo que afirma el valor positivo de las culturas o de la diversidad cultural, y que aspira a elaborar los mecanismos jurídicos que las protejan, fomenten y hagan perdurar en el tiempo. Esta es una aspiración amplia e indeterminada. Observando más detalladamente, lo que podemos identificar son múltiples y diversas políticas multiculturales, en ocasiones incluso antagónicas. Sin embargo, a pesar de su multiplicidad, estas políticas tienen un mínimo común denominador. Ellas apuntan a garantizar e implementar derechos especiales cuya justificación se deja retrotraer a razones de identidad cultural y que, correspondientemente, otros individuos que son miembros de la comunidad jurídica y política, pero no comparten esa identidad o membrecía cultural, no pueden reclamar legítimamente. Demás está indicar que esta concepción se opone al concepto de ciudadanía que caracteriza a las sociedades democráticas y políticamente liberales. En éstas, el estatus legal del ciudadano es caracterizado mediante su igualdad frente al Estado. Una crítica multicultural central es que estos derechos liberales no harían justicia a los grupos culturales. En esta línea afirma Okin que las demandas multiculturales más discutidas refieren a

la exigencia hecha, básicamente, en el contexto de democracias liberales, de que culturas minoritarias o formas de vida no son suficientemente protegidas por la práctica de asegurar los derechos individuales de sus miembros y

\footnotetext{
${ }^{5}$ MARSHALL, Thomas H. Citizenship and Social Class.

${ }^{6}$ RAWLS, John. A Theory of Justice.
} 
que, en consecuencia, ellos deben ser protegidos a través de derechos especiales de grupo o privilegios. $^{7}$

La motivación a la base de muchas políticas multiculturales es loable: la evidente situación de desventaja, injusticia y desprotección, tanto en perspectiva histórica como sistémica, de la que son víctimas muchos grupos culturales y sus miembros. Desde esta perspectiva, los derechos culturales diferenciados están llamados a corregir estas injusticias. Además, serían mecanismos apropiados para generar y fortalecer la paz social. Derechos diferenciados en razón de la pertenecía étnica, cultural o religiosa son realidad en muchas jurisdicciones nacionales. Ellos están en consonancia con documentos directrices del derecho internacional. Sin embargo, no están exentos de controversia. Sus detractores consideran que no se basan en argumentos de justicia y que sus consecuencias sociales pueden ser devastadoras. Esta crítica se expresa sobre todo desde una perspectiva política liberal: derechos diferenciados generan conjuntos de oportunidades diferentes y, de este modo, sancionan marcos variables de libertad para los ciudadanos en razón de la pertenencia cultural. Dicho de otro modo, se generan privilegios vinculados a la persona (y no al cargo) en razón de su cultura. Si el estatus legal del ciudadano se caracteriza por la igualdad de los ciudadanos frente al Estado, el que éste último genere y sancione mediante herramientas jurídicas distintos marcos de libertad según la pertenencia étnica, cultural o religiosa de sus ciudadanos es un despropósito. Después de todo, esta situación no se diferenciaría estructuralmente de situaciones de trato diferenciado desfavorable, como, por ejemplo, la situación de los esclavos en sociedades esclavistas, la situación de las mujeres en sociedades patriarcales, etc. Situaciones de evidente injusticia, ante las cuales la garantía de la ciudadanía igual para todos sería, e históricamente ha sido, la respuesta apropiada. Por encima de esto, las consecuencias podrían ser devastadoras: en el proceso de interacción social las desigualdades en derechos producen el control de las elites locales, la exclusión social, etc., y ponen en peligro el cemento de la sociedad y la paz social. Desde la perspectiva de sus defensores la analogía con el trato desigual discriminatorio no sería aceptable. Después de todo, lo que anima a muchas de las políticas multiculturales es el respeto y el reconocimiento de la dignidad humana, que se entiende en estrecha relación a la pertenencia cultural. Sólo a la base del reconocimiento

\footnotetext{
${ }^{7}$ OKIN, Susan Moller. "Is Multiculturalism Bad for Women?", p. 10-11.
} 
social y jurídico de la diferencia cultural sería posible generar sociedades cooperativas y estables.

\section{Relativismo cultural y derechos culturales}

Una tesis usual en el debate multicultural refiere a la conexión entre pertenencia y auto-respeto. En "The Politics of Recognition" ${ }^{8}$, un artículo que constituye uno de los hitos fundadores en el desarrollo conceptual del multiculturalismo, Charles Taylor sostiene la tesis de que el autorespeto de los individuos depende del reconocimiento del grupo cultural al que se pertenece por parte de los otros, porque esta pertenencia influye de un modo determinante en la identidad de los individuos. ${ }^{9}$ Derechos especiales permitirían llevar a cabo este reconocimiento. Desde esta perspectiva, la pretensión de reconocimiento a la base de la utopía multicultural debiese ser universal: todas las culturas deberían ser reconocidas por parte de los otros para así no violar el auto-respeto de sus miembros. Esto se expresaría mediante derechos culturales especiales que protegiesen las diversas prácticas culturales.

Una aplicación extrema de esta tesis la encontramos en Strange Multiplicity de James Tully ${ }^{10}$. En este libro, él critica lo que entiende como una doctrina constitucional moderna. Su caracterización coincide con la supuesta concepción de persona a la base de las teorías liberales profusamente criticada por los autores comunitaristas (una concepción individualista, egoísta, desarraigada, etc. - compare por ejemplo Sandel ${ }^{11}$ ). De más está decir que ésta es una representación distorsionada de una doctrina constitucional que se caracteriza por afirmar derechos y principios universalmente vinculantes. Pero según Tully, se trata de una doctrina sesgada que lleva a la dominación de algunos, las mayorías culturales, por sobre otros, las minorías culturales. Su propuesta es, entonces, lo que él denomina una constitución contemporánea, esto es, una constitución que reconoce la diversidad cultural, porque es concebida "como una forma de acomodación de la diversidad cultural".

Como cabe esperar, Tully critica las posiciones universalistas. Pero también critica las posiciones que apelan a entendimientos compartidos

\footnotetext{
${ }^{8}$ TAYLOR, Charles. "The Politics of Recognition".

${ }^{9}$ En otro sitio he investigado esta teoría (cf. LOEWE, Daniel. "La política del reconocimiento").

${ }^{10}$ TULLY, James. Strange Multiplicity. Constitutionalism in an Age of Diversity.

${ }^{11}$ SANDEL, Michael. Liberalism and the limits of justice.
} 
en sociedades nacionales (como por ejemplo propone Walzer ${ }^{12}$ con su teoría de las esferas de la justicia). Esto se debe a que, evidentemente, siempre hay grupos disidentes al momento de establecer la mejor interpretación de la tradición nacional. Y lo que a Tully le interesa es el reconocimiento legal de las prácticas y normativas de todos los grupos culturales dentro de la sociedad, también de aquellos que no comparten los entendimientos compartidos. A diferencia de las teorías mencionadas, según su propia teoría una condición suficiente para considerar una práctica particular como permitida es que sea parte de alguna cultura. En este sentido, es una concepción cultural convencionalista. ¿Hace posible el constitucionalismo convencionalista multicultural evitar y/o solucionar los conflictos que se generan en una sociedad caracterizada por la coexistencia de diversos grupos culturales? Esto es discutible.

Primero: las condiciones de imposibilidad para la realización de la situación utópica pueden ser variadas. Quizás no están aun disponibles los recursos psicológicos o tecnológicos para llevarla a cabo. Quizás los intereses políticos y fácticos se oponen. Podemos seguir enumerando condiciones de imposibilidad. Sin embargo, hay una condición incompatible con el pensamiento utópico: la imposibilidad lógica. La razón es evidente: si una situación utópica no es realizable porque viola las reglas de la lógica, la utopía deja de ser una situación ideal y se transforma en fantasía. Trate de imaginar una sociedad utópica que se caracteriza porque en ella todos ganan más que el promedio. Si entendemos la utopía multicultural como una organización social y política que garantiza todo el espacio jurídico y social necesario para que todos los grupos culturales y sus miembros puedan desarrollar cada una de sus prácticas culturales tradicionales, surge un problema de compatibilidad lógica. El problema es que el reconocimiento jurídico de todas las culturas implica un propósito incoherente: "El inevitable problema es que culturas tienen un contenido proposicional"13. De este modo hay problemas de composición. Esto implica que dos cosas que son posibles, no pueden ser simultáneamente posibles. La existencia de una descarta la existencia de la otra o incluso atribuye a la otra una existencia imposible. ${ }^{14}$ Los diferentes contenidos proposicionales de la culturas determinan que algunas cosas son verdaderas y otras falsas, que algunas son correctas y otras no. Pero si esto es así, entonces tenemos problemas

\footnotetext{
${ }^{12}$ WALZER, Michael. Spheres of Justice: A Defense of Pluralism and Justice.

${ }^{13}$ BARRY, Brian. Culture and Equality. An Egalitarian Critique of Multiculturalism, p. 270.

${ }^{14}$ WALDRON, Jeremy. "Cultural Identity and Civic Responsibility", p. 159.
} 
con la composición. Yo no puedo decir que aquello que mi cultura sostiene es correcto, y que aquello que otra cultura afirma también lo es, aunque desde la perspectiva de mi cultura aquello debería ser entendido como falso. Si el reconocimiento de una cultura es el reconocimiento de su valor (como sea que se lo entienda), entonces por referencia al criterio que utilicemos para determinar el valor, algunas culturas serán más valiosas que otras, y por tanto más dignas de reconocimiento en relación al criterio utilizado. Y esto vale con independencia de cuáles sean estos criterios. De este modo, resulta absurdo afirmar que todas las culturas deben ser igualmente reconocidas. A menos, claro, que se trate de una hipocresía.

Segundo: una estrategia para evitar la conclusión anterior es abrazar el relativismo cultural. Esto es lo que hace Tully. El relativismo cultural es un tipo de relativismo, según el cual las culturas son universos normativos independientes. Así, no tiene sentido referirse al valor de una cultura en base a criterios ajenos a ella. "Cultura" es aquí una categoría autojustificada. Lo que mi cultura sostiene es correcto, porque ella lo sostiene, y lo que otras culturas sostienen, también es correcto, porque ellas lo sostienen. Pero el relativismo cultural es una tesis difícil de aceptar. El Apartheid en Sudáfrica, el sistema de castas en India o la esclavitud en los estados del sur de los Estados Unidos antes de la guerra civil no eran ni son moralmente aceptables porque son una parte de nuestra cultura, como los defensores de esas instituciones podrían haber afirmado o pueden afirmar. De la misma manera la opresión de las mujeres en Afganistán, la mutilación genital femenina, la violencia intrafamiliar, las prácticas de linchamiento del Ku-Klux-Klan, las prácticas discriminatorias ampliamente aceptadas, el sacrificio humano, los delitos sexuales y la larga lista de casos multiculturales, no son moralmente aceptables porque sean parte de nuestra cultura.

Tercero: el convencionalismo cultural jurídico que se basa en el relativismo cultural es fuente de conflictos. Los conflictos surgen en la interacción, coordinación y cooperación de individuos o grupos que consideran como vinculantes órdenes normativos con demandas que rivalizan entre sí. Es el problema de Romeo y Julieta: una innovación romántica de la que no pueden dar cuenta las tradiciones y que conduce a conflicto. Waldron refiere al caso mencionado para señalar la importancia de una 
structure of rights that people can count on for organizing their lives, a structure which stands somewhat apart from communal or affective attachments and which can be relied on to survive as a basis for action no matter what happens to those attachments. ${ }^{15}$

Considere el caso que presenta el mismo Tully para mostrar las supuestas bondades de su sistema de acomodación y reconocimiento de todas las diferencias culturales dentro de un orden jurídico. Tully se refiere al caso de la Salish Indian band. Thomas era por nacimiento un miembro de esta tribu que tiene una reserva en el nordeste de Canadá. Él no creció en la reserva, no vivía en ésta, conocía poco de la cultura de los Salish y no estaba especialmente interesado en ésta. A pesar de esto fue secuestrado por los miembros y se lo obligó a participar en un rito de iniciación. Thomas demandó exitosamente a los victimarios por "asalto, golpizas y robo de libertad". La corte argumentó "que la Danza Espíritu y, más específicamente, el involuntario aspecto de ésta, no era una característica central del modo de vida de los Salish"16. De acuerdo a Tully, en este caso "los derechos fueron tomados en serio" porque las diferencias culturales fueron consideradas. ${ }^{17}$ Pero lo que él afirma es que, porque la Danza Espíritu y el carácter involuntario de ésta no son centrales para la cultura de los Salish, entonces Thomas tiene derecho a protección. ¿Qué pasaría, entonces, si ésta u otra práctica cultural fuese un aspecto central de la cultura? Esto no es sólo normativamente sospechoso, como afirme en el punto anterior. También es fuente permanente de conflictos.

Cuarto: el convencionalismo jurídico es conservador. En cuanto tal, esto no es problemático. Lo problemático es que los ordenes tradicionales que el convencionalismo jurídico sanciona están sesgados en desmedro de algunos de sus integrantes, y estos suelen ser los más débiles, entre otros, mujeres, niños y minorías sexuales. ${ }^{18}$ Considere la idea de los entendimientos compartidos que caracterizarían a ciertos grupos, ya sean sociedades nacionales como en la teoría de Walzer ${ }^{19}$, o subgrupos culturales dentro de estas sociedades. Si los hay, estos entendimientos no se dejan retrotraer a la participación en igual pie de todos los miembros de la cultura, sino que son un destilado de las opiniones de todos aquellos que históricamente han tenido el poder para hacer sus puntos de vista

\footnotetext{
${ }^{15}$ WALDRON, Jeremy. "When Justice Replaces Affection: The Need for Rights", p. 625-634.

${ }^{16}$ TULLY, op. cit., p. 172.

${ }^{17}$ Ibidem

${ }^{18}$ OKIN, op. cit.

${ }^{19}$ WALZER, op. cit.
} 
vinculantes. Y estas diferencias de poder se reproducen en las demandas multiculturales que aspiran a generar las condiciones jurídicas que permitan seguir manteniendo el statu quo de dominación. En un artículo acerca de los derechos legales y las reclamaciones culturales de algunos grupos de inmigrantes en Gran Bretaña, Sebastian Poulter refiere al rol de la mujeres como "un ejemplo muy claro" del "choque de culturas"20. Aquí hay "matrimonios de niños, matrimonios forzados, sistemas de divorcio que desaventajan a las mujeres, poligamia y cliterictomía"21. La mayoría de los casos se dejan retrotraer a acusaciones de mujeres y niñas, cuyos derechos individuales fueron violados de acuerdo a las prácticas culturales de sus grupos. Si atendemos a las voces de los sin voz, es evidente que el reconocimiento jurídico de las prácticas de todas las culturas desaventaja legalmente a los más desaventajados en cada tradición.

\section{Igualdad y derechos culturales}

Para argumentar a favor del multiculturalismo, no es necesario sostener tesis extremas como las discutidas. Hay versiones multiculturales moderadas que no comparten la tesis relativista acerca del valor ni la tesis acerca del reconocimiento de todas las culturas. Por el contrario, se sostiene la validez universal e irrestricta de ciertos derechos fundamentales o derechos humanos, pero simultáneamente se apunta al hecho de que muchas veces las normas y leyes universalmente válidas en una sociedad tienden a desaventajar a todos aquellos que no comparten la cultura mayoritaria. Expresado con otras palabras, la cultura mayoritaria sería lo más parecido a un bien público, y todos aquellos que no la comparten se verían perjudicados porque no pueden escapar a las consecuencias adveras para su cultura que trae consigo la disposición general de este bien (mediante leyes, políticas públicas, normativas, medioambiente social, etc.), y porque en la generación de sus propios bienes culturales tienen que invertir recursos extras que deben sustraer a otros planes, mientras que todos los que comparten la cultura mayoritaria pueden dar por descontada la disposición de sus propios bienes culturales. La estrategia argumentativa recurre al concepto de igualdad y trata de dar cuenta de las implicancias que trae consigo una consideración multicultural de la igualdad. Una fortaleza de esta concepción es que puede recurrir, al menos

\footnotetext{
${ }^{20}$ POULTER, Sebastian. "Ethnic Minority Customs, English Law and Human Rights", p. 589-615.

${ }^{21}$ OKIN, op. cit., p. 17.
} 
parcialmente, a algunas de las premisas igualitarias más en boga dentro de la filosofía política contemporánea post Rawls y así buscar eco en las filas del hoy en día profusamente sostenido liberalismo igualitario. Según la interpretación multicultural igualitaria, tomar la igualdad en serio conlleva la aceptación de algunos derechos culturales. La utopía multicultural que de aquí se desprende es más moderada que la anteriormente discutida. La utopía seria una sociedad en la que nadie es desaventajado por su pertenencia cultural en tanto no viole los derechos fundamentales de otros - entendiendo estos últimos de un modo restrictivo.

Un modo de articular esta tesis es por referencia al concepto de neutralidad que muchas teorías liberales consideran como uno de sus núcleos fundacionales. Contra la pretensión liberal se sostiene que las reglas y normas en cualquier sociedad, también en una sociedad liberal, no son neutrales. Por el contrario, ellas desaventajan a ciertas culturas o individuos en razón de su pertenencia cultural y aventajan a otros que usualmente pertenecen a las culturas mayoritarias. Garantizar la igualdad implicaría otorgar derechos especiales para que los miembros de culturas desaventajadas por las normas no-neutrales de la sociedad puedan tener acceso a la igualdad de oportunidades. Expresado con los términos de Parekh, se requiere de un entendimiento culturalmente sensitivo de la igualdad. ${ }^{22}$ Esta argumentación es atractiva, pero adolece de dificultades que hay que considerar.

Primero: la neutralidad liberal no es de resultados, como esta argumentación presupone. Es absurdo criticar a la doctrina liberal porque no podría ofrecer un punto igualmente equidistante de todos los demás. El liberalismo, y ciertamente también el liberalismo político, propone una concepción normativa. De este modo, no puede tener los mismos efectos en todas las formas de vida. Formas de vida que incluyen prácticas que coliden con derechos básicos liberales, como por ejemplo la mutilación genital femenina, serán desaventajadas en comparación a otras formas de vida, siendo así su consecución más difícil o derechamente imposible. Esto es deseable porque está en consonancia con la doctrina normativa liberal que determina lo que es justo. Y esto vale en relación a formas de vida escritas con o sin una gramática cultural. El sentido de la neutralidad liberal refiere a los modos de justificación: no podemos favorecer, o desfavorecer, a ciertos individuos o formas de vida porque estos individuos

\footnotetext{
${ }^{22}$ PAREKH, Bhikhu. Rethinking Multiculturalism. Cultural Diversity and Political Theory.
} 
o formas de vida son más, o menos, valiosas. ${ }^{23}$ Rawls refiere, de un modo algo distinto, a "neutrality of aim"24.

Segundo: afirmar que el impacto desigual de normas generales en diferentes formas de vida es injusto, desconoce que cualquier norma general aventaja a algunos más que a otros, pero no por esto es injusta. Como anticipamos en el primer punto, en determinadas circunstancias es el impacto desigual lo que puede hacerla justa: el impuesto al tabaco desaventaja más a los fumadores que a los no fumadores. De hecho, estos últimos se ven favorecidos. Límites de velocidad desaventajan a todos aquellos que gustan de la velocidad, pero no a todos aquellos que de cualquier modo conducirían de un modo prudente. Resumiendo: el impacto desigual de una regla no implica que sea injusta. Por cierto, puede ser un indicio de injusticia. Pero en este caso hay que mostrar con un examen cuidadoso en qué consiste la injusticia. ${ }^{25}$

Tercero: la interpretación sensitiva de la igualdad debe recurrir a la tesis de que las preferencias con una base cultural o religiosa tienen un estatus especial. Pero no parecen haber razones concluyentes para considerar las preferencias con un origen cultural como diferentes de las sin este origen de un modo moralmente relevante que justifique derechos culturales para satisfacer las primeras pero no las segundas. ¿Es acaso el vegetarianismo de un budista moralmente más relevante que el mío que se basa en razones morales? ¿Es acaso la objeción de conciencia por motivos religiosos más respetable que la de aquel que se opone secularmente a una guerra particular por considerarla injusta? A continuación consideraré algunos argumentos que se han articulado para justificar esta supuesta prioridad.

Un argumento corriente a favor de la prioridad de las preferencias culturales y religiosas es que su frustración implicaría costos particularmente altos. Este argumento tiene sentido, sobre todo en el caso de preferencias religiosas que suelen asociarse con costos infinitos. Para un Amish está en juego la salvación del alma si es que conduce velozmente un automóvil de colores. Pero el argumento no es conclusivo. Aquel que contra su conciencia moral secular debe participar en una guerra injusta en la que puede morir y sobre todo, matar, debe asumir grandes costos, sin duda superiores a los de un judío o musulmán que no come carne porque el

\footnotetext{
${ }^{23}$ ACKERMAN, Bruce. Social Justice in the Liberal State.

${ }^{24}$ RAWLS, John. Political Liberalism.

${ }^{25}$ BARRY, op. cit.
} 
sacrificio ritual de animales (Sechita o Halah) no está permitido en una jurisdicción particular. Si este argumento puede probar algo, es que hay diferencias cuantitativas en los costos que surgen debido a la frustración en la satisfacción de preferencias. Pero este argumento no puede establecer que haya una diferencia cualitativa entre las preferencias con y sin origen cultural o religioso, que permita favorecer a las primeras pero no a las segundas.

Otra argumentación para distinguir las preferencias con un origen cultural o religioso de otras sin este origen, es afirmar que las primeras, a diferencia de las segundas, no son escogidas. Por lo tanto no se debe ser considerado moralmente responsable por los costos que implica su satisfacción. Sin embargo, este argumento tampoco puede justificar esta diferenciación.

En primer lugar, no es claro en qué sentido "escogemos" nuestras preferencias. ¿He escogido mi preferencia por helado de chocolate? Preferencias tienen una persistencia psicológica independiente de las acciones. Lo que hago, es escoger un determinado curso de acción (lo que los economistas llaman "preferencias reveladas"): comprar helado de chocolate (o de vainilla, si el de chocolate es muy caro), comer Kosher, o asistir a misa los domingos, etc. Pero en esta elección por un curso de acción no hay diferencia alguna con las elecciones que realizan individuos en base a razones seculares: asistir a los partidos de baloncesto los martes en la mañana, etc. Y si esto es así, no se entiende porque uno debiese ser privilegiado por sobre el otro.

Hasta un determinado punto sí se puede establecer una diferencia: la frustración de preferencias culturales y sobre todo religiosas mediante la no realización de las prácticas correspondientes puede violar la libertad de conciencia. Ciertamente, el valor de la libertad de conciencia es central no sólo desde una perspectiva liberal. La conciencia de cada cual refiere a temas últimos acerca de la existencia humana y nuestro lugar en el cosmos, y de este modo otorga valor a nuestra vida haciéndonos seres humanos íntegros. Dentro de los aspectos más importantes de una vida humana está el ser capaz de buscar un entendimiento del significado último de la vida. ${ }^{26}$ Por el contrario, bajo condiciones normales no asistir

\footnotetext{
${ }^{26}$ Martha Nussbaum argumenta insistentemente a favor de esta tesis en su interpretación del enfoque en las capacidades (NUSSBAUM, Martha. Frontiers of Justice; IDEM. Liberty of Conscience. In Defense of American's Tradition of Religious Equality; IDEM. The Clash Within. Democracy, Religious Violence, and India's Future; Women and Human Development).
} 
al juego de baloncesto los martes en la mañana no parece violar la libertad de conciencia de nadie. Por lo tanto, y en relación a los costos implicados, se podría justificar sancionar un marco de libertad más amplio en el primer caso mediante el reconocimiento de derechos especiales (por ejemplo, excepciones de reglas generales relativas a los horarios de un maestro de tiempo completo) pero no en el segundo -aunque ciertamente el amante de baloncesto preferiría disponer de una excepción que lo libere de las reglas relativas a los horarios de trabajo para poder practicar su deporte los martes en la mañana. Pero aunque esto sea así, y hay buenas razones para sostenerlo, de esto no se deducen razones para privilegiar la libertad de conciencia religiosa o cultural por sobre la libertad de conciencia secular. La protección de la conciencia no se agota con la protección de la libertad religiosa o cultural. En nuestras sociedades plurales muchos individuos tienen una conciencia moral secular. Si se protege mediante excepciones la libertad de conciencia de los primeros, también se debe proteger la de los segundos. ${ }^{27}$

En segundo lugar, si lo que genera una diferencia cualitativa entre los dos tipos de preferencia es que las con una base cultural o religiosa no son escogidas, esta teoría no puede dar cuenta de las preferencias culturales o religiosas de todos aquellos que sí han escogido (en el sentido limitado que se le puede dar a este acto de libertad) su pertenencia cultural y religiosa, como advenedizos y conversos. Así, por ejemplo, sólo aquellos que han nacido como musulmanes tendrían una demanda legítima a una excepción para faltar los viernes en la tarde a su obligación de maestro de escuela de tiempo completo para poder asistir a la mezquita, pero no un converso al islam. Y sólo los indígenas americanos nacidos y socializados como tales tendrían una demanda legítima a consumir peyote (un alucinógeno a mezcalina) pero no advenedizos. Pero esto es, ciertamente, arbitrario.

En tercer lugar, de muchos individuos que han sido socializados en ciertos enclaves de estilos de vida no podemos decir que hayan escogido sus preferencias, al menos no de un modo que se distinga de los miembros de grupos culturales y religiosos. Si esto es así, entonces no se puede justificar una consideración cualitativamente diferente de estos dos tipos de pertenencia. Pero en general, los defensores de derechos culturales no están a favor de derechos culturales en razón de la pertenecía a un enclave de estilo de vida: vida aristocrática y bucólica, new age, pokemones,

${ }^{27}$ Cf. LOEWE, Daniel. "Libertad de conciencia y liberalismo". 
etc., sino que consideran que, a diferencia de los miembros de grupos culturales y religiosos, los individuos que pertenecen a estos enclaves de estilos de vida deben cargar con los costos de sus propias preferencias.

Por último, hay pertenecías culturales que no son no-escogidas, y que, sin embargo, desde la óptica de algunos defensores del multiculturalismo sí generarían demandas legítimas a derechos culturales. Por ejemplo, la demanda de los Rastafaris para consumir marihuana en sus sesiones reflexivas. Si lo que les otorga un estatus especial a las preferencias con un origen cultural es que no fueron escogidas, entonces Rastafaris y otros grupos de adscripción voluntaria no tendrían demandas legítimas a derechos culturales.

Cuarto: un entendimiento culturalmente sensitivo de la igualdad, como el que Parekh ${ }^{28}$ propone, se basa en un malentendido acerca de lo que es la igualdad de oportunidades. Una discapacidad física o la falta de poder económico pueden limitar el conjunto de nuestras oportunidades disponibles. Es por esto que en un contexto liberal igualitario se puede argumentar a favor de una compensación de usuarios de sillas de rueda, etc. ${ }^{29}$, o incluso a favor de derechos sociales que garanticen libertades sustantivas, como propone Amartya $\operatorname{Sen}^{30}$, o el igual valor de la libertad, como propone Rawls ${ }^{31}$. Esto sería necesario para igualar lo más posible el conjunto de oportunidades disponibles. Pero una creencia cultural no limita nuestro conjunto de oportunidades, sino que actualiza algunas y no otras, pero las oportunidades siguen siendo las mismas para todos. No realizar esta diferenciación implica afirmar que la situación de una mujer que no puede tener relaciones sexuales a causa de una mutilación genital femenina es la misma, que la de una mujer que no las tiene en razón de creencias religiosas.

\section{Identidad y cultura}

"Identidad" es un concepto profusamente utilizado en las ciencias sociales. Se recurre a él tanto para dar un fundamento conceptual a la cooperación social y sus ventajas como para explicar el surgimiento de conflictos y su perseverancia. En los debates multiculturales la referencia a la identidad juega un papel fundamental.

\footnotetext{
${ }^{28}$ PAREKH, op. cit.

${ }^{29}$ DWORKIN, Ronald. "What is equality? Part 2: Equality of resources", p. 283-345.

${ }^{30}$ SEN, Amartya. Development as Freedom.

${ }^{31}$ RAWLS, John. "The Basic Liberties and their Priority".
} 
Podemos identificar dos modos contrapuestos de entender la relación entre la identidad cultural y la identidad individual. Estos son extremos de un continuo. En un extremo encontramos, recurriendo a los conceptos de Amartya Sen ${ }^{32}$, un entendimiento "singular" de la identidad humana. De acuerdo a este entendimiento, profusamente compartido en las defensas multiculturales, se considera a los seres humanos como pertenecientes únicamente a un grupo. Evidentemente no se niega que los individuos pueden pertenecer a múltiples grupos de afinidad (clubs, gremios, de preferencias musicales o culinarias, etc.). El punto es que todas estas identidades se supeditan a una considerada como fundamental: la cultural, que a menudo es entendida de un modo étnico-cultural o religioso. Un ejemplo de este entendimiento singular lo encontramos, por ejemplo, a la base de la teoría del reconocimiento sostenida por Taylor ${ }^{33}$. Pero también lo podemos atisbar a la base de múltiples teorías de carácter más moderado cuando, por ejemplo, sostienen que la pertenencia a un contexto cultural rico y seguro - caracterizado en base a una lengua y una historia compartida - es necesario para que los individuos puedan actuar autónomamente, ${ }^{34}$ o cuando caracterizan a los grupos culturales como comprehensivos, esto es grupos en los cuales la cultura permea múltiples aspectos de la vida social e individual. ${ }^{35}$

En el otro extremo encontramos una consideración "cosmopolita" de la identidad. De acuerdo a este entendimiento, las fuentes identitarias son múltiples y diversas. ${ }^{36}$ Esta concepción es más apropiada para nuestro mundo. En sociedades abiertas, los individuos desarrollan múltiples imágenes de sí mismos. Por ejemplo, en relación a los roles familiares, al mundo del trabajo, a las creencias religiosas o no religiosas, a las posiciones políticas, a la pertenencia étnica, al lenguaje, al género, a la orientación sexual, a las actividades de esparcimiento, a las preferencias culinarias, etc. Por tanto, no es evidente que los individuos dependan de una de sus identidades sociales, como la relativa al grupo cultural que debe ser protegida con derechos culturales, de un modo tan fundamental, que su reconocimiento sea condición del auto-respeto. Restringir la identidad humana a sólo una, que debe gozar de prioridad por sobre

\footnotetext{
${ }^{32}$ SEN, Amartya. Identity and Violence. The illusion of destiny.

${ }^{33}$ TAYLOR, op. cit.

${ }^{34}$ KYMLICKA, Will. Liberalism, Community and Culture; IDEM. Multicultural Citizenship, op. cit.

35 MARGALIT, Avishai; RAZ, Joseph. "National Self-Determination"; MARGALIT, Avishai. The Decent Society; SELZNICK, Philip. The Moral Commonwealth: Social Theory and the Promise of Community.

${ }^{36} \mathrm{SEN}$, Identity and Violence, op. cit.; WALDRON, Jeremy. "Cultural Identity and Civic Responsibility".
} 
todas las demás, implica una concepción reduccionista del ser humano y constituye una arbitrariedad con consecuencias devastadoras.

A nivel individual, la consideración singular de la identidad apunta en una dirección muy diferente a la que parece ser apropiada en nuestro mundo. En sociedades abiertas, en las que los individuos tienen numerosas imágenes de sí mismos, la capacidad para establecer relaciones empáticas hacia otras identidades es central para poder desarrollar una identidad estable. ${ }^{37}$ En el trato con numerosas y diversas expectativas es importante tener la capacidad de distanciarse de los roles propios y mantener una posición tolerante en relación a las ambigüedades. Por el contrario, en buena parte del multiculturalismo encontramos la afirmación de una identidad singular, celosa y omnipresente.

A nivel social, el reconocimiento de nuestras múltiples identidades y así el reconocimiento de nuestras identidades compartidas, en último término nuestra humanidad ${ }^{38}$, es un antídoto contra la intransigencia y chauvinismo propio de tantas culturas y tradiciones (o de las élites de los grupos culturales en su lucha por acceder o por mantener el poder). Este es un punto de partida productivo para evitar conflictos o su resolución violenta. Recurriendo a una analogía muy utilizada: los impactos en los parabrisas tenían consecuencias devastadoras. Para evitar que el impacto de un proyectil atravesase el parabrisas, hiriendo a los ocupantes del automóvil, la solución fue introducir una fina y tupida malla. De este modo, la fuerza del impacto se reparte en todo el parabrisas y el proyectil no penetra al interior. El caso de las múltiples identidades es similar: la red tejida en razón de múltiples identidades hace posible controlar los efectos destructivos devastadores de un conflicto particular.

\section{Utopía multicultural reconsiderada}

En muchos programas multiculturales encontramos un entendimiento singular de la identidad. Como he examinado, este entendimiento lleva a políticas multiculturales con consecuencias moralmente inaceptables. La utopía cultural se transforma en una antiutopía. El querer más (más derechos, más reconocimiento, etc.) implica, en este caso, menos. Esto no implica que no pueda haber programas multiculturales que reconozcan la variedad de las identidades humanas.

\footnotetext{
${ }^{37}$ MEYER, Thomas. Identity Mania. Fundamentalism and the Politicization of Cultural Differences.

${ }^{38}$ NUSSBAUM, Martha. Cultivating Humanity; IDEM, "Patriotism and Cosmopolitism".
} 
Por ejemplo, en el caso de los inmigrantes es posible proponer medidas como la adopción del multiculturalismo en los currículos escolares; la inclusión de representación étnica o al menos sensibilidad con respecto a esta representación en los medios públicos o en los procesos de licencias de medios; excepciones de códigos de ropa, legislación de cierre de negocios los domingos, etc.; permitir la doble nacionalidad; financiamiento de de organizaciones étnicas para promover actividades culturales y financiamiento de educación bilingüe o enseñanza en la lengua materna; programas de acción afirmativa para grupos de inmigrantes desaventajados. Pero en cada uno de estos casos hay que reconocer la prioridad de lo que algunos autores denominan "individualismo reflexivo" ${ }^{39}$. Esta es la idea que nuestras identidades son múltiples y que en cada caso estamos llamados a sopesar la importancia de cada una de estas identidades y a interpretarla a la luz de todo aquello que somos.

Ciertamente no todo tipo de identidad es accesible para cada individuo. Este es también el caso de cualquier decisión. Pero el que las opciones estén limitadas, no implica que los individuos no puedan escoger. Ciertamente una identidad puede influenciar nuestras decisiones, pero éstas no están determinadas. Es siempre el individuo el que debe examinar y determinar la importancia y significancia de sus múltiples identidades en los diferentes contextos de vida. ${ }^{40}$ La referencia a nuestras facultades racionales es aquí insoslayable. Esta perspectiva reconoce la riqueza y el carácter multifacético de los seres humanos. Una política multicultural puede celebrar la diferencia cultural. Pero sólo bajo el reconocimiento de la libertad de los individuos para definir y redefinir constantemente su identidad del modo que consideren apropiado. Esto implica que los derechos culturales no pueden coartar las opciones de los individuos y por tanto sus libertades, y deben estar siempre supeditados al reconocimiento de nuestra humanidad compartida. Este tipo de programas multiculturales puede ser productivo en la generación de simpatías mutuas que contengan y contrarresten las tendencias sectarias tan prolijamente cultivadas en muchas culturas.

En esta utopía multicultural, en caso de constituir una, todos los individuos disponen del mismo espacio para poder desarrollar sus prácticas culturales en tanto no violen los derechos de otros. De este modo, la discriminación injustificada en razón de la pertenencia cultural,

\footnotetext{
${ }^{39}$ SEN, Identity and Violence, op. cit.; APPIAH, Kwame Anthony. The Ethics of Identity.

${ }^{40}$ SEN, Identity and Violence, op. cit., p. 29 e ss.
} 
ya sea la discriminación de los miembros de un grupo por parte de individuos que no pertenecen a él, la discriminación de miembros de grupos culturales por parte de otros miembros, y la discriminación de no miembros por parte de miembros, está descartada. Esta utopía no nos lleva mucho más allá de la ciudadanía entendida mediante la igualdad de derechos y deberes. $Y$ en este sentido, si estas propuestas tienen un carácter utópico, corresponden, utilizando los conceptos de Rawls ${ }^{41}$, a un tipo de utopía realista, es decir una representación que amplía el marco de los que podemos considerar como realizable.

\section{Bibliografía}

ACKERMAN, Bruce. Social Justice in the Liberal State. New Haven, London: Yale University Press, 1980.

APPIAH, Kwame Anthony. The Ethics of Identity. Princeton: Princeton University Press, 2005.

BARRY, Brian. Culture and Equality. An Egalitarian Critique of Multiculturalism. Polity Press, 2001.

COHEN, Joshua (ed.). For Love of Country. Debating the Limits of Patriotism. Boston: Beacon Press, 1996.

COHEN, Joshua; HOWARD, Matthew; NUSSBAUM, Martha (eds.). Is Multiculturalism Bad for Women? Susan Moller Okin With Respondents. Princeton: Princeton University Press, 1999.

DWORKIN, Ronald. "What is equality? Part 2: Equality of resources", in Philosophy and Public Affairs, v. 10, n. 4, 1981, p. 283-345.

FURNIVALL, John S. Colonial Policy and Practice. Cambridge: Cambridge University Press, 1948.

GUTMANN, Amy (ed.). Multiculturalism. Princeton: Princeton University Press, 1994.

KUKATHAS, Chandran. "Are there any cultural rights?", in Political Theory, v. 20, n. 1, 1992, p. 105-139.

. "Cultural Toleration", in SHAPIRO, KYMLICKA, op. cit.

. The liberal archipelago. Oxford: Oxford University Press, 2003.

KYMLICKA, Will (ed.). The Rights of Minority Cultures. Oxford: Oxford University Press, 1997. 1989.

. Liberalism, Community and Culture. Oxford: Oxford University Press, . Multicultural Citizenship. Oxford: Oxford University Press, 1995.

\footnotetext{
${ }^{41}$ RAWLS, John. The law of peoples with "The idea of public reason revisited".
} 
KYMLICKA, Will; NORMAN, Wayne. Citizenship in diverse societies. Oxford: Oxford University Press, 2000.

LOEWE, Daniel. "La política del reconocimiento", in Véritas, v. 51, n. 4, 2006, p. 61-79.

. "Libertad de conciencia y liberalismo", in Anuario de Derechos Humanos, Facultad de Derecho, Universidad de Chile, 2011.

MARGALIT, Avishai. The Decent Society. Cambridge Mass: Harvard University Press, 1996.

MARGALIT, Avishai; RAZ, Joseph. "National Self-Determination", in The Journal of Philosophy v. 87, n. 9, 1990, p. 439-461.

MARSHALL, Thomas H. Citizenship and Social Class. London: Pluto Press, 1992 (1950).

MEYER, Thomas. Identity Mania. Fundamentalism and the Politicization of Cultural Differences. New Delhi: Mosaic Books, 2001; original: IdentitätsWahn: Die Politisierung des kulturellen Unterschieds. Aufbau TaschenbuchVerlag, 1997.

NUSSBAUM, Martha. Cultivating Humanity. Cambridge: Harvard University Press, 1997.

. Frontiers of Justice. Cambridge, Mass: Harvard University Press, 2006. . Liberty of Conscience. In Defense of American's Tradition of Religious Equality. New York: Basic Books, 2008.

. The Clash Within. Democracy, Religious Violence, and India's Future.

Cambridge, Mass: Harvard University Press, 2007.

.Women and Human Development. Cambridge, Harvard University Press, 2000.

. "Patriotism and Cosmopolitism", in COHEN, For love..., op. cit.

OKIN, Susan Moller. "Is Multiculturalism Bad for Women?", in COHEN, HOWARD, NUSSBAUM, op. cit.

PAREKH, Bhikhu. Rethinking Multiculturalism. Cultural Diversity and Political Theory. London: Macmillan Press, 2000.

POULTER, Sebastian. "Ethnic Minority Customs, English Law and Human Rights", in International and Comparative Law Quarterly, v. 36, 1987, p. 589-615.

RAWLS, John. "The Basic Liberties and their Priority", in STERLING, McMurring (ed.). The Tanner Lectures on Human Values, v. 3, Salt Lake City: University of Utah Press, 1982.

. A Theory of Justice. Cambridge: Harvard University Press, 1971.

. Political Liberalism. New York: Columbia University Press, 1993.

. The law of peoples with "The idea of public reason revisited".

Cambridge: Harvard University Press, 1999. 
SANDEL, Michael. Liberalism and the limits of justice. Cambridge: Cambridge University Press, 1982.

SELZNICK, Philip. The Moral Commonwealth: Social Theory and the Promise of Community. Berkeley: University of California Press, 1992.

SEN, Amartya. Development as Freedom. Nueva York: Anchor Books, 1999. . Identity and Violence. The illusion of destiny. New York, London: Norton, 2006.

SHAPIRO, Ian; KYMLICKA, Will (eds.). Ethnicity and group rights. Nomos XXXIX. New York University Press, 1997.

SMITH, M.G. The plural society in British West Indies. Los Angeles: University of California Press, 1965.

TAYLOR, Charles. "The Politics of Recognition", in GUTMANN, op. cit.

TULLY, James. Strange Multiplicity. Constitutionalism in an Age of Diversity. Cambridge: Cambridge University Press, 1995.

WALDRON, Jeremy. "Cultural Identity and Civic Responsibility", in KYMLICKA, NORMAN, op. cit.

. "Minority Cultures and the Cosmopolitan Alternative", in KYMLICKA,

The Rights of..., op. cit.,

. "When Justice Replaces Affection: The Need for Rights", in Journal of Law and Public Policy, v. 11, p. 625-634, 1988.

WALZER, Michael. Spheres of Justice. Basic Books, 1984.

YOUNG, Iris Marion. Justice and the Politics of Difference. Princeton: Princeton University Press, 1990.

\section{Abstract}

\section{The multicultural utopia}

According to the article a multicultural utopia, understood as a social and legal structure that guarantees to all cultural and religious groups enough space to develop all their traditional practices, is an anti-utopia in which rights can be violated on behalf of culture. A multicultural policy that does not violate the rights of individuals must recognize and respect their freedom in order to constantly define and redefine their identity in an appropriate way.

Keywords: Multiculturalism; Utopia; Relativism; Identity; Cultural Rights.

Recibido para publicación en 05/04/2012.

Aceptado para publicación en 03/05/2012.

Received for publication on April, 05 $5^{\text {th }}, 2012$.

Accepted for publication on May, 03 ${ }^{\text {th }}, 2012$. 